\title{
Exogenous hydrogen sulfide protects against hepatic ischemia/reperfusion injury by inhibiting endoplasmic reticulum stress and cell apoptosis
}

\author{
LIANG CHEN $^{1 *}$, KEQIANG MA $^{1 *}$, HAINING FAN $^{2}$, XIAOLONG WANG $^{1}$ and TIANSHENG CAO ${ }^{1}$ \\ ${ }^{1}$ Department of General Surgery, Affiliated Huadu Hospital of Southern Medical University \\ (People's Hospital of Huadu District), Guangzhou, Guangdong 510800; ${ }^{2}$ Department of Hepatopancreatobiliary Surgery, \\ the Affiliated Hospital of Qinghai University, Xining, Qinghai 810001, P.R. China
}

Received November 27, 2020; Accepted May 5, 2021

DOI: $10.3892 /$ etm.2021.10231

\begin{abstract}
The aim of the present study was to explore the effect of exogenous hydrogen sulphide $\left(\mathrm{H}_{2} \mathrm{~S}\right)$ on endoplasmic reticulum (ER) stress (ERS) in a rat model of hepatic ischemia/reperfusion (I/R) injury. A total of 48 Sprague-Dawley rats were randomly divided into four groups (n=12/group) as follows: Sham, I/R, I/R preceded by NaHS (I/R-NaHS) and I/R preceded by L-C-propargylglycine (PAG), a $\mathrm{H}_{2} \mathrm{~S}$ inhibitor (I/R-PAG). With the exception of the sham group, the rats in the other groups were subjected to $30 \mathrm{~min}$ hepatic warm ischemia followed by reperfusion for 6 or $12 \mathrm{~h}$. Hepatic function was evaluated by serum concentrations of alanine aminotransferase (ALT). Apoptosis of hepatic cells was assessed by TUNEL staining and measurement of caspase-12 expression. The expression levels of ERS-associated proteins and mRNAs of pancreatic ER eukaryotic translation initiation factor-2a kinase (PERK), activating transcription factor-6 (ATF6), glucose-regulated protein (GRP) 78, TNF-receptor-associated factor (TRAF)-2, C/EBP homologous protein (CHOP) and caspase-12 were also measured by western blotting and reverse transcription-quantitative PCR. The serum concentrations of ALT in the I/R and I/R-PAG groups were found to be significantly higher compared with those in the sham and I/R-NaHS
\end{abstract}

Correspondence to: Professor Haining Fan, Department of Hepatopancreatobiliary Surgery, the Affiliated Hospital of Qinghai University, 251 Ningda Road, Xining, Qinghai 810001, P.R. China E-mail: fanhaining2020@163.com

Dr Xiaolong Wang, Department of General Surgery, Affiliated Huadu Hospital of Southern Medical University (People's Hospital of Huadu District), 48 Xinhua Road, Guangzhou, Guangdong 510800, P.R. China

E-mail: wangxiaolong2020@yeah.net

*Contributed equally

Key words: hydrogen sulfide, hepatic ischemia/reperfusion, endoplasmic reticulum stress groups after $6 \mathrm{~h}$ of reperfusion; in addition, the ALT level returned to normal in the I/R group, while it increased further in the I/R-PAG group after $12 \mathrm{~h}$ of reperfusion. A higher cell apoptosis rate was observed in the I/R and I/R-PAG groups and the highest cell apoptosis rate was observed in the I/R-PAG group; correspondingly, the expression of caspase-12 was increased in the I/R and I/R-PAG groups. $\mathrm{H}_{2} \mathrm{~S}$ appeared to significantly attenuate hepatic I/R-induced ERS response, as indicated by the decreased expression of ATF6, PERK, GRP78, TRAF2 and CHOP. Endogenous $\mathrm{H}_{2} \mathrm{~S}$ may serve a hepatoprotective function after I/R, and inhibition of endogenous $\mathrm{H}_{2} \mathrm{~S}$ results in aggravation of $\mathrm{I} / \mathrm{R}$ damage. Exogenous $\mathrm{H}_{2} \mathrm{~S}$ was shown to inhibit ERS-related gene expression, leading to suppression of inflammatory reaction and improvement of I/R damage. Therefore, exogenous $\mathrm{H}_{2} \mathrm{~S}$ has therapeutic potential to alleviate hepatic I/R injury.

\section{Introduction}

Liver injury after the onset of reperfusion is the result of the interplay between different complex mechanisms, with cellular damage occurring during both the ischemic and reperfusion phases. Hepatic ischemia/reperfusion (I/R) causes major injury following vascular occlusion during both liver surgery and liver transplantation (1); however, its pathogenesis is largely unknown. The destructive effects of I/R may be triggered by the acute generation of reactive oxygen species (ROS) and nitrogen species after reoxygenation, which cause a chain reaction of cellular responses leading to inflammation, cell death and, eventually, organ failure (2-4). Several mediators, such as proinflammatory cytokines, ROS, adhesion molecules, chemokines and excess nitric oxide (NO) contribute to this injury (5). However, it was previously demonstrated that reperfusion did not induce oxidative stress, but sustained endoplasmic reticulum (ER) stress (ERS) in the livers of rats subjected to traumatic-hemorrhagic shock (6). The reason may be that the model used in that study was produced by bleeding until decompensation, followed by an inadequate or adequate reperfusion phase.

The ER is an organelle with important signaling and homeostatic functions, which is responsible for protein 
folding, maturation and trafficking. ERS is a particular subcellular pathological process involving an imbalance of homeostasis and ER disorder. In the early stages of ERS, cells exhibit a protective unfolded protein response that changes the cellular transcriptional and translational programs to alleviate this process (7). ERS triggers an adaptive response pathway, named the unfolded protein response (UPR) pathway, through activation of pancreatic ER eukaryotic translation initiation factor-2a kinase (PERK), inositol requiring enzyme-1 (IRE1) and activating transcription factor-6 (ATF6). Several conditions, including hypoxia, I/R injury, neurodegeneration, heart disease and diabetes, may be associated with activation of ER-initiated cell death pathways (8). In samples from human livers subjected to I/R, UPR pathway activation was observed (9). Therefore, ERS may play an important role in hepatic I/R injury.

Endogenous hydrogen sulfide $\left(\mathrm{H}_{2} \mathrm{~S}\right)$ is increasingly being recognized as an important gaseous physiological mediator synthesized from cysteine by cystathionine $\gamma$ lyase (CSE) and other naturally occurring enzymes. CSE is differentially expressed in the cardiovascular, neuronal, immune, renal, respiratory, gastrointestinal, reproductive, hepatic and endocrine systems (10). $\mathrm{H}_{2} \mathrm{~S}$ serves important functions in cytoprotection, anti-inflammation, nociceptive stimulation, regulation of insulin release and longevity (11-13). Acute administration of $\mathrm{H}_{2} \mathrm{~S}$, either prior to ischemia or at reperfusion, ameliorates hepatic I/R injury through an upregulation of intracellular antioxidant and antiapoptotic signaling pathways (14). However, whether ERS is involved in hepatic I/R injury remains unclear.

It was hypothesized that exogenous/endogenous $\mathrm{H}_{2} \mathrm{~S}$ inhibited ERS through limiting the extent of I/R injury. The present study was undertaken to investigate the effects of exogenous $\mathrm{H}_{2} \mathrm{~S}$ on I/R injury using an in vivo rat model. The aim was to determine whether exogenous $\mathrm{H}_{2} \mathrm{~S}$ can inhibit the expression of ERS- and cell apoptosis-related genes, thereby leading to suppression of inflammatory reactions and improvement of I/R damage, and whether inhibition of endogenous $\mathrm{H}_{2} \mathrm{~S}$ may result in aggravation of $\mathrm{I} / \mathrm{R}$ injury.

\section{Materials and methods}

Animal model. In total, 48 Sprague-Dawley male rats, aged 10 weeks (weighing 225-275 g) were supplied by The Animal Centre of Xining, Qinghai Province and housed in groups of two to four in $40 \times 60 \times 30 \mathrm{~cm}$ plastic cages with soft bedding under a 12-h day/night cycle. The room temperature was maintained at $22 \pm 1^{\circ} \mathrm{C}$ and relative humidity was $45-60 \%$; water and food pellets were available ad libitum. Animal studies were performed in compliance with the guidelines of animal ethics of Qinghai University and were approved by the Ethics Committee Qinghai University Affiliated Hospital (approval no. 20180152; Xining, China).

Experimentaldesign and surgery. A total of 48 Sprague-Dawley rats were randomly divided into four groups (n=12 group) as follows: Sham, I/R, I/R preceded by NaHS (I/R-NaHS) and I/R preceded by L-C-propargylglycine (PAG), a $\mathrm{H}_{2} \mathrm{~S}$ inhibitor (I/R-PAG). All surgeries were performed as previously described (15). All animals were anesthetized with 5\% isoflu- rane for induction and 2-3\% isoflurane for maintenance in an acrylic anesthesia chamber, and the liver was exposed through a transverse abdominal incision. A 30-min period of hepatic warm ischemia was introduced by cross-clamping the hepatoduodenal ligament with a microvascular clamp (Pringle's maneuver) in the rats, with the exception of those in the sham group. Subsequently, the clamps were removed to allow reperfusion for 6 or $12 \mathrm{~h}$ before sampling, in order to explore whether the I/R injury could be reversed under the protective effect of $\mathrm{H}_{2} \mathrm{~S}$. The animals of the I/R group were administered saline ( $1 \mathrm{ml} / \mathrm{kg}$ body weight) intraperitoneally before closing the incision. The animals of the I/R-NaHS group were administered a single dose $(56 \mu \mathrm{mol} / \mathrm{kg})$ of NaHS intraperitoneally $30 \mathrm{~min}$ before closing the incision (the dosage was set according to our preliminary experiment). To completely inhibit endogenous $\mathrm{H}_{2} \mathrm{~S}$, the animals of the I/R-PAG group were administered $50 \mathrm{mg} / \mathrm{kg}$ of PAG intraperitoneally $30 \mathrm{~min}$ before and after closure of the incision. After the experiments were completed, all the rats were euthanized with $8 \%$ isoflurane inhalation for 30 min until breathing had stopped and their skin became cyanotic.

Serum biochemical analysis. At the end of the reperfusion period, 100- $\mu$ l blood samples were collected from the aorta under anesthesia using heparinized syringes. The rats were euthanized after blood sample collection and liver samples were harvested. After $300 \times$ g centrifugation at $4^{\circ} \mathrm{C}$ for $30 \mathrm{~min}$, plasma was separated and stored at $-20^{\circ} \mathrm{C}$ until analysis. Serum concentrations of alanine aminotransferase (ALT; cat. no. E-BC-K235-M, Elabscience Biotechnology, Inc.) were measured at $37^{\circ} \mathrm{C}$ using standard enzymatic techniques (Ektachem 700 analyzer; Kodak).

TUNEL assay. The harvested liver samples were snap-frozen in liquid nitrogen and stored in $-80^{\circ} \mathrm{C}$. Subsequently, the frozen liver samples were cut into $5-\mu \mathrm{m}$ sections, and in situ apoptosis was detected using a TUNEL assay kit (Promega Corporation): Proteinase $\mathrm{K}$ was used to incubate the liver tissue samples for at $4^{\circ} \mathrm{C} 20 \mathrm{~min}$, before $50 \mu \mathrm{l}$ terminal deoxynucleotidyl transferase incubation buffer was utilized to incubate the samples for $1 \mathrm{~h}$ at $37^{\circ} \mathrm{C}$ in the dark after the samples were washed for three times with PBS, $0.5 \mu \mathrm{g} / \mathrm{ml}$ DAPI (Beyotime Institute of Biotechnology) was used to stain the nucleus for $15 \mathrm{~min}$ at room temperature. The sections were then dehydrated in $100 \%$ ethanol, cleared with xylene and mounted coverslips cell-side down on clean glass using a fluorescence-compatible mounting medium (Vectashield; Vector Laboratories, Inc.). Cells displaying brown staining within the nucleus were counted as apoptotic. The number of apoptotic cells was counted by an investigator who was blinded to the group assignment by examining three non-overlapping microscopic fields of view under high-power magnification $(x 400)$ via a Zeiss confocal Axioskop 2 Plus microscope (Carl Zeiss AG) and expressed as percentage (16).

Western blot analysis. Ischemic hepatic lobes were dissected and homogenized in a buffer [2\% SDS, $50 \mathrm{mM}$ DTT, $62.5 \mathrm{mM}$ Tris (pH 6.8), $10 \%$ glycerol] containing $1 \mathrm{mM}$ PMSF (Amresco, LLC). The samples were then boiled for $5 \mathrm{~min}$ and centrifuged at 7,500 x g for $10 \mathrm{~min}$ at $4^{\circ} \mathrm{C}$. Supernatants 
Table I. Primers for quantitative PCR amplification.

\begin{tabular}{|c|c|c|c|}
\hline Gene & Primer sequence $\left(5^{\prime} \rightarrow 3^{\prime}\right)$ & Expected size (bp) & GenBank accession no. \\
\hline ATF6 & $\begin{array}{l}\text { Forward: GGCTTCCTCCAGTTGTTC } \\
\text { Reverse: GTGACAGGCTTCTCTTCC }\end{array}$ & 177 & NM_001107196.1 \\
\hline PERK & $\begin{array}{l}\text { Forward: TGTCTTGGTTGGGTCTGATG } \\
\text { Reverse: CCTTCTTGCGGATGTTCTTG }\end{array}$ & 215 & NM_031599.2 \\
\hline GRP78 & $\begin{array}{l}\text { Forward: TAATCAGCCCACCGTAAC } \\
\text { Reverse: GTTTCCTGTCCCTTTGTC }\end{array}$ & 193 & NM_013083.2 \\
\hline TRAF2 & $\begin{array}{l}\text { Forward: CTCTTCTTCGTGGTGATG } \\
\text { Reverse: TGCTCTCGGTTGTTATGG }\end{array}$ & 101 & NM_001107815.2 \\
\hline $\mathrm{CHOP}$ & $\begin{array}{l}\text { Forward: GGAGAAGGAGCAGGAGAATG } \\
\text { Reverse: GAGACAGACAGGAGGTGATG }\end{array}$ & 176 & NM_001109986.1 \\
\hline Caspase-12 & $\begin{array}{l}\text { Forward: ACTGTCCGAGTCTGAGAAAC } \\
\text { Reverse: AGTGGCTATCCCTTTGCTTGTG }\end{array}$ & 104 & NM_130422.1 \\
\hline GAPDH & $\begin{array}{l}\text { Forward: TGCCACTCAGAAGACTGTGG } \\
\text { Reverse: GGATGCAGGGATGATGTTCT }\end{array}$ & 85 & AF106860.2 \\
\hline
\end{tabular}

PERK, pancreatic ER eukaryotic translation initiation factor-2a kinase; ATF6, activating transcription factor-6; GRP78, glucose-regulated protein 78; TRAF2, TNF-receptor-associated factor 2; CHOP, C/EBP homologous protein.

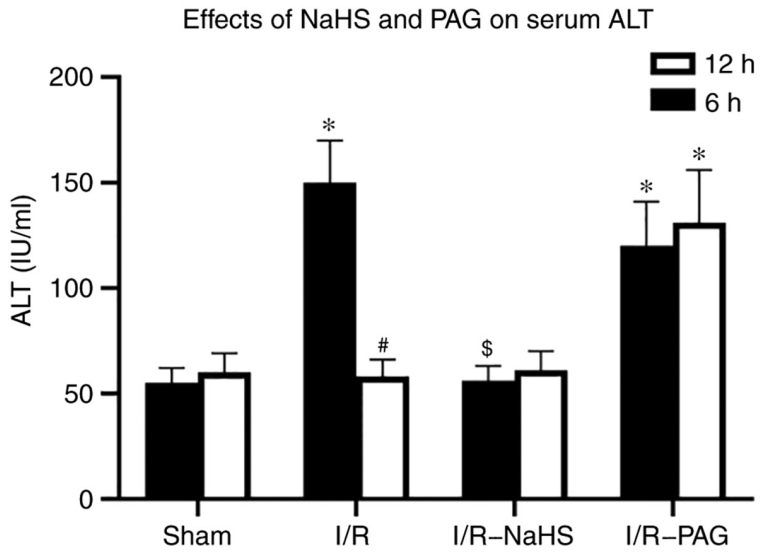

Figure 1. Effects of NaHS and PAG on serum ALT levels after hepatic I/R. Serum ALT level (IU/ml) was measured in sham-operated rats or in rats subjected to $30 \mathrm{~min}$ of hepatic ischemia followed by 6 and $12 \mathrm{~h}$ of reperfusion treated with saline (I/R group), NaHS (I/R-NaHS group) or PAG (I/R-PAG group). Each bar represents the mean \pm SEM of three separate repeated experiments. ${ }^{*} \mathrm{P}<0.05$ vs. sham group; ${ }^{*} \mathrm{P}<0.05$ vs. $6 \mathrm{~h} ;{ }^{\$} \mathrm{P}<0.05$ vs. I/R group. PAG, L-C-propargylglycine; I/R, ischemia/reperfusion; ALT alanine aminotransferase.

were collected and protein concentrations were determined using a Bradford Protein Assay kit (Beyotime Institute of Biotechnology). Protein samples $(35 \mu \mathrm{g})$ were then loaded and separated on a $12 \%$ SDS-PAGE. Following transfer onto a nitrocellulose membrane, the membranes were incubated with $5 \%$ skimmed milk to block non-specific antigens at room temperature for $2 \mathrm{~h}$ and probed with rabbit polyclonal antibodies (all 1:1,000) against ATF6 (cat. no. ab203119, Abcam), PERK (cat. no. ab65142, Abcam), glucose-regulated protein (GRP)78 (ab21685, Abcam), TNF-receptor-associated factor (TRAF)-2 (cat. no. ab62488, Abcam), C/EBP homologous protein (CHOP; cat. no. ab11419, Abcam), caspase-12 (cat. no. ab62463, Abcam) and GAPDH (cat. no. ab9485,
Abcam) overnight at $4^{\circ} \mathrm{C}$. Following incubation with 1:1,000 diluted goat anti-rabbit $\operatorname{IgG}(\mathrm{H} \& \mathrm{~L})$ secondary antibody (cat. no. G-21234, Themo Fisher Scientific) for $2 \mathrm{~h}$ at room temperature, the protein bands were developed using an enhanced chemiluminescence kit (Amersham; Cytiva).

Reverse transcription-quantitative $(R T-q) P C R$ analysis. Total RNA was isolated from liver tissue using TRIzol ${ }^{\circledR}$ reagent (Thermo Fisher Scientific, Inc.) according to the manufacturer's instructions and reversely transcribed using PrimeScript ${ }^{\mathrm{TM}} \mathrm{RT}$ reagent kit (Takara Bio, Inc.) at $37^{\circ} \mathrm{C}$ for $45 \mathrm{~min}$ and then $95^{\circ} \mathrm{C}$ for $5 \mathrm{~min}$. cDNA was used as the template for the $\mathrm{qPCR}$ reaction. The $\mathrm{PCR}$ conditions were as follows: Step 1, pre-denaturing at $95^{\circ} \mathrm{C}$ for $30 \mathrm{sec}$; step 2, 40 cycles at $94^{\circ} \mathrm{C}$ for $5 \mathrm{sec}$, followed by $60^{\circ} \mathrm{C}$ for $30 \mathrm{sec}$. qPCR was performed with SYBR ${ }^{\mathrm{TM}}$ Green Master Mix kit (cat. no. 4344463; Thermo Fisher Scientific, Inc.) using AB 2900HT fluorescence ration PCR instrument. The primers for qPCR amplification are listed in Table I. For determination of relative quantification, the expression levels of the genes were calculated and expressed based on the $2^{-\Delta \Delta \mathrm{Cq}}$ method (17). GAPDH was selected as an internal control gene.

Statistical analysis. Data are expressed as mean \pm SEM of three separate repeated experiments. Two-way ANOVA followed by Bonferroni's post hoc test was performed to assess variation among experimental groups. $\mathrm{P}<0.05$ was considered to indicate statistically significant differences. All analyses were performed with SPSS 16.0 (SPSS Inc.).

\section{Results}

$\mathrm{H}_{2} \mathrm{~S}$ restores liver function following $I / R$ and inhibition of endogenous $\mathrm{H}_{2} \mathrm{~S}$ results in aggravation of $I / R$ damage. In order to assess hepatocellular damage due to I/R, the serum ALT concentration was measured. A marked increase in the 


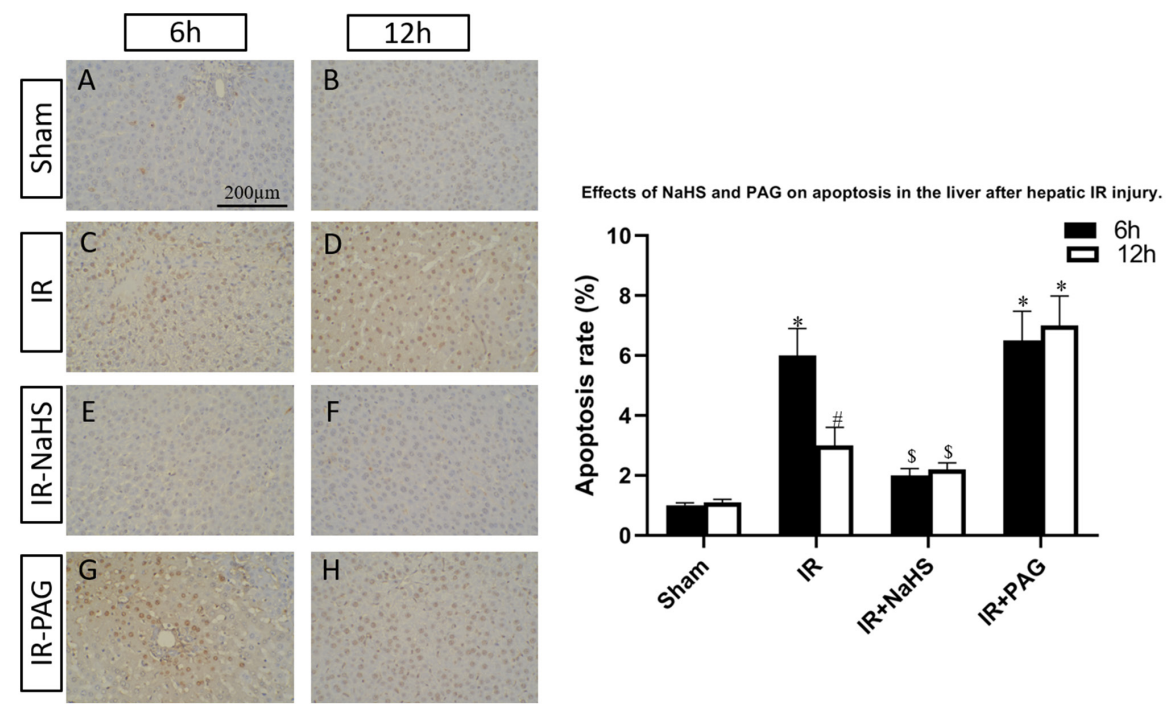

Figure 2. Effects of NaHS and PAG on hepatocyte apoptosis following hepatic I/R injury. Livers were harvested at (A-D) $6 \mathrm{~h}$ and (E-H) $12 \mathrm{~h}$ after reperfusion and TUNEL assay was performed to detect the percentage of apoptotic cells in the (A and E) sham, (B and F) I/R, (C and G) I/R-NaHS and (D and H) I/R-PAG groups. Each bar represents the mean \pm SEM of three separate repeated experiments. ${ }^{*} \mathrm{P}<0.05$ vs. sham group; ${ }^{*} \mathrm{P}<0.05$ vs. $6 \mathrm{~h} ;{ }^{\$} \mathrm{P}<0.05$ vs. I/R group. PAG, L-C-propargylglycine; I/R, ischemia/reperfusion.

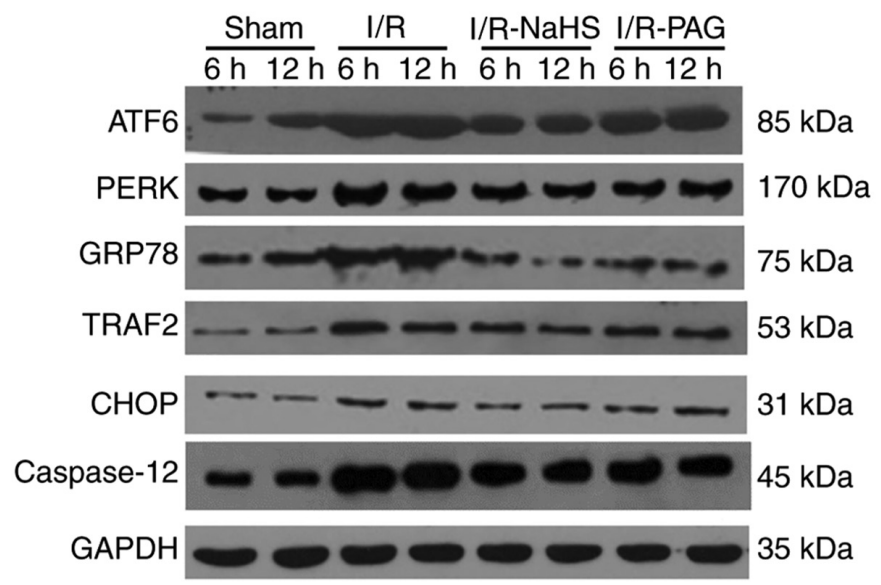

Figure 3. Western blotting was used to examine the levels of the endoplasmic reticulum stress-associated ATF6, PERK, GRP78, TRAF2, CHOP and caspase-12 proteins. PERK, pancreatic ER eukaryotic translation initiation factor-2a kinase; ATF6, activating transcription factor-6; GRP78, glucose-regulated protein 78; TRAF2, TNF-receptor-associated factor 2; CHOP, C/EBP homologous protein.

ALT level was observed in the I/R group compared with that in the Sham group after $6 \mathrm{~h}$ of reperfusion and the ALT level returned to normal in the $\mathrm{I} / \mathrm{R}$ group compared with that in the Sham group after $12 \mathrm{~h}$ reperfusion (Fig. 1). Pretreatment with NaHS prevented the elevations in ALT levels $6 \mathrm{~h}$ after I/R compared with those in the I/R group. A significant increase in the ALT level was observed in the I/R-PAG group after 6 and $12 \mathrm{~h}$ of reperfusion compared with those in the Sham group. These results indicated that endogenous $\mathrm{H}_{2} \mathrm{~S}$ may have a protective function in liver I/R, and exogenous $\mathrm{H}_{2} \mathrm{~S}$ ameliorates hepatic I/R injury.

$\mathrm{H}_{2} \mathrm{~S}$ ameliorates cell apoptosis in $I / R$ and inhibition of endogenous $\mathrm{H}_{2} \mathrm{~S}$ results in aggravation of cell apoptosis. To investigate the functions of $\mathrm{H}_{2} \mathrm{~S}$ during liver I/R, the I/R-rats were pretreated with $\mathrm{NaHS}$ or the endogenous $\mathrm{H}_{2} \mathrm{~S}$ inhibitor, PAG. TUNEL assay was performed to assess the percentage of apoptotic cells in the livers of the rats of the four groups.
As shown in Fig. 2, the hepatic cell apoptosis induced by I/R was decreased by NaHS intervention; however, the apoptosis rate was increased in the I/R-PAG group compared with the I/R group after 6 and $12 \mathrm{~h}$ of reperfusion. Next, total protein and mRNA were extracted from the livers and the expression levels of caspase-12, which is an apoptosis-promoting protease, were detected in the four groups. As shown in Figs. 3 and 4, caspase-12 was highly expressed in the I/R and I/R-PAG groups, while no difference in caspase-12 expression was found between the I/R-PAG and I/R groups. More importantly, NaHS intervention significantly alleviated I/R-induced caspase-12 upregulation.

$\mathrm{H}_{2} \mathrm{~S}$ inhibits ERS and inhibition of endogenous $\mathrm{H}_{2} \mathrm{~S}$ results in aggravation of ERS induced by $I / R$ injury. To investigate the molecular mechanism underlying the protective effects of $\mathrm{H}_{2} \mathrm{~S}$, the protein and mRNA levels of ERS-associated molecules were analyzed in liver tissue by western blot and 

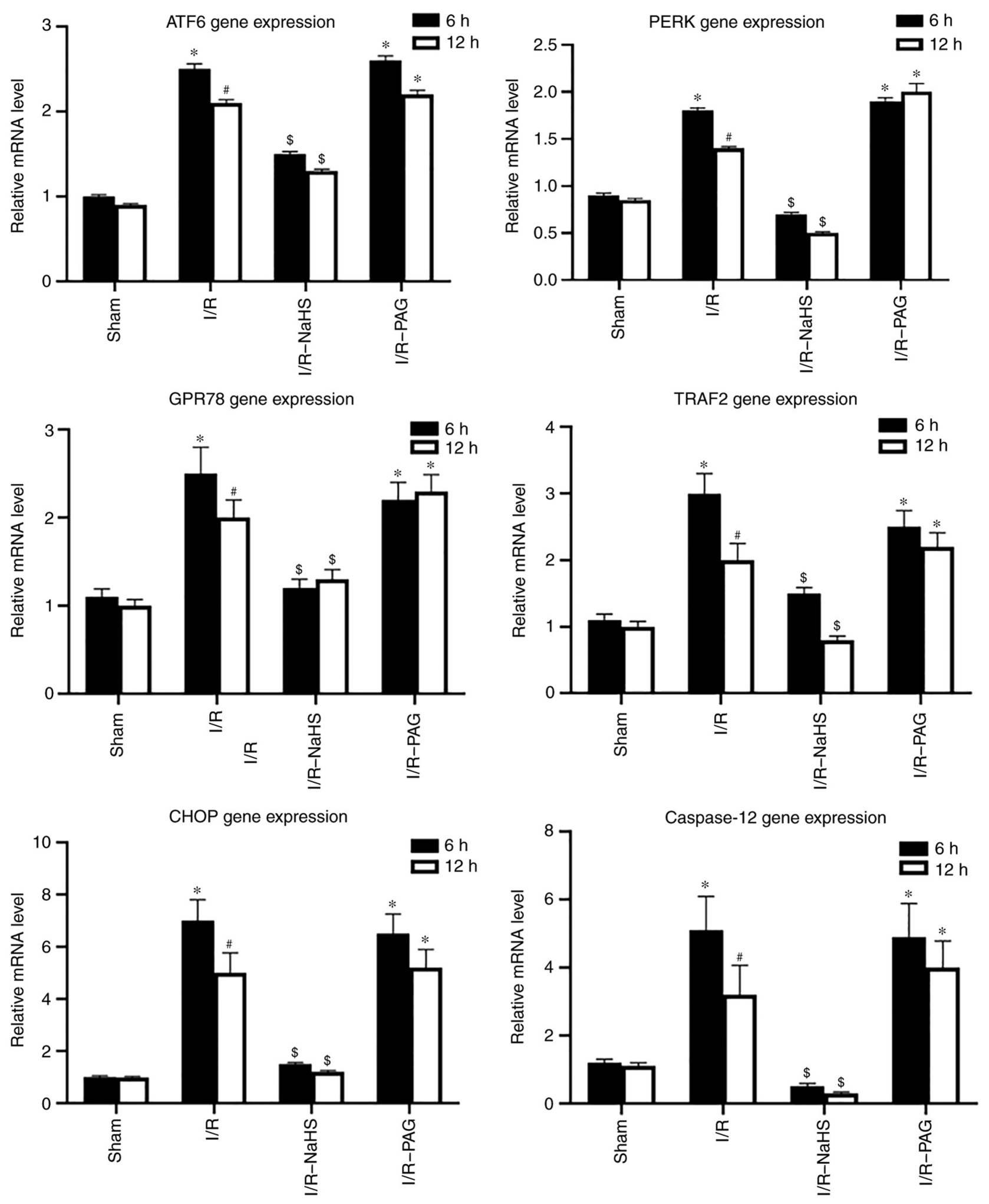

Figure 4. Reverse transcription-qPCR analysis was used to examine the mRNA levels of endoplasmic reticulum stress-associated genes. Each bar represents the mean \pm SEM of three separate repeated experiments. ${ }^{*} \mathrm{P}<0.05$ vs. sham group; ${ }^{*} \mathrm{P}<0.05 \mathrm{vs} .6 \mathrm{~h}$; ${ }^{5} \mathrm{P}<0.05 \mathrm{vs}$. I/R group. I/R, ischemia/reperfusion; PERK, pancreatic ER eukaryotic translation initiation factor-2a kinase; ATF6, activating transcription factor-6; GRP78, glucose-regulated protein 78; TRAF2, TNF-receptor-associated factor 2; CHOP, C/EBP homologous protein.

RT-qPCR assays. As shown in Figs. 3 and 4, the protein and mRNA levels of ATF6, PERK, GRP78, TRAF2 and CHOP in the liver were markedly elevated by $\mathrm{I} / \mathrm{R}$, whereas NaHS treatment attenuated the stimulatory effect of I/R on ATF6, PERK, GRP78, TRAF2 and CHOP protein and mRNA levels. PAG treatment exerted no obvious effect on the action of $\mathrm{I} / \mathrm{R}$ on the protein and mRNA levels of ATF6, PERK, GRP78, TRAF2 and CHOP compared with the I/R group; therefore, it was inferred that endogenous $\mathrm{H}_{2} \mathrm{~S}$ may be involved in pathways other than ERS-related pathways. 


\section{Discussion}

The present study demonstrated that exogenous $\mathrm{H}_{2} \mathrm{~S}$ treatment, using NaHS as the $\mathrm{H}_{2} \mathrm{~S}$ donor, reduced I/R injury, whereas inhibition of endogenous $\mathrm{H}_{2} \mathrm{~S}$ by PAG treatment aggravated $\mathrm{I} / \mathrm{R}$ injury in a hepatic $\mathrm{I} / \mathrm{R}$ rat model. In accordance with histological results, serum ALT measurement demonstrated that the levels of ALT were elevated in the I/R and I/R-PAG groups, indicating that $\mathrm{H}_{2} \mathrm{~S}$ has a hepatoprotective function against I/R. Similar with previous findings, whereby Na2S was used as the $\mathrm{H}_{2} \mathrm{~S}$ donor, $\mathrm{H}_{2} \mathrm{~S}$ attenuated the elevation of ALT after I/R (14).

The present study further demonstrated that the protective effect of $\mathrm{H}_{2} \mathrm{~S}$ was associated with its attenuation of ERS induced by hepatic I/R injury, as the protein and mRNA expression of ERS-associated molecules, including ATF6, PERK, GRP78, TRAF2 and CHOP, were inhibited by NaHS treatment. A previous study also demonstrated that $\mathrm{H}_{2} \mathrm{~S}$ exerts protective effects on the cardiovascular system, as it attenuates cardiomyocytic ERS induced by hyperhomocysteinemia in rats (18). ERS-induced apoptosis may play a significant role in the pathophysiology of I/R injury $(19,20)$. ERS triggers the UPR pathway, which has three branches, involving IRE1, PERK and ARF6 (21). GRP78, an indicator of UPR pathway activation also referred to as immunoglobulin heavy chain-binding protein, is a central regulator of ER function due to its roles in protein folding and assembly, targeting of misfolded proteins for degradation, ER $\mathrm{Ca}^{2+}$ binding and controlling the activation of transmembrane ERS sensors (21). Induction of GRP78 has been widely used as a marker for ERS and the onset of the UPR. Due to its antiapoptotic properties, stress induction of GRP78 represents an important prosurvival component of the evolutionarily conserved UPR (22). Active IRE1 recruits the adaptor TRAF2, which activates apoptosis via the c-Jun N-terminal kinase pathway $(23,24)$. CHOP was originally identified in response to DNA damage, and the CHOP level is a sensitive indicator of ERS (23). Caspase-12 is an enzyme that mediates ER-specific apoptosis and cytotoxicity $(25,26)$ and it was found to be highly expressed in the I/R and I/R-PAG groups, while no difference in caspase-12 expression was found between the I/R-PAG and I/R groups. Therefore, caspase-12 may not play an important part in the process of apoptosis that is caused by inhibition of endogenous $\mathrm{H}_{2} \mathrm{~S}$. A previous study also demonstrated that traumatic-hemorrhagic shock or reperfusion induces early and persistent ERS of the liver or nitrosylative stress $(6,27)$. The present study demonstrated that NaHS treatment attenuated the stimulatory action of I/R on ATF6, PERK, GRP78, TRAF2 and CHOP protein and mRNA levels, which was consistent with the findings of the aforementioned previous studies.

Endogenous $\mathrm{H}_{2} \mathrm{~S}$ is a gaseous mediator produced by CSE in numerous tissues, including the liver (28). The enzymatic activity of CSE was found to be inhibited by PAG (29). To determine the contribution of endogenous $\mathrm{H}_{2} \mathrm{~S}$ to liver protection against I/R, PAG was used to inhibit the production of endogenous $\mathrm{H}_{2} \mathrm{~S}$. Low levels of $\mathrm{H}_{2} \mathrm{~S}$ in the body result in severe damage following I/R injury, with marked elevation of ALT levels. However, the expression levels of ERS- and cell apoptosis-related genes from I/R-PAG rats were similar with those in $\mathrm{I} / \mathrm{R}$ rats. Therefore, endogenous $\mathrm{H}_{2} \mathrm{~S}$ may also be involved in pathways other than ERS-related pathways.

In summary, the present study demonstrated that exogenous $\mathrm{H}_{2} \mathrm{~S}$ can effectively ameliorate I/R-induced injury along with decreased protein and mRNA expression of ERS-associated molecules, including ATF6, PERK, GRP78, TRAF2 and CHOP. $\mathrm{I} / \mathrm{R}$ was shown to induce ERS and activate ERS-related apoptosis pathways, whereas inhibition of endogenous $\mathrm{H}_{2} \mathrm{~S}$ led to aggravation of damage after $\mathrm{I} / \mathrm{R}$ and exogenous $\mathrm{H}_{2} \mathrm{~S}$ markedly reduced I/R injury. However, these conclusions were drawn based on the results of the hepatic I/R rat model constructed in the present study and they must be interpreted with caution, as the underlying molecular mechanisms require further investigation.

\section{Acknowledgements}

Not applicable.

\section{Funding}

No funding was received.

\section{Availability of data and materials}

The datasets used and/or analyzed during the current study are available from the corresponding author on reasonable request.

\section{Authors' contributions}

HNF and XLW conceived the study. LC and KQM participated in all the experiments; XLW and TSC analyzed the data; LC drafted the manuscript. HNF, XLW and KQM have seen and confirm the authenticity of the raw data. All authors have read and approved the final version of this manuscript. All authors agree to be accountable for all aspects of the work in ensuring that questions related to the accuracy or integrity of any part of the work are appropriately investigated and resolved.

\section{Ethics approval and consent to participate}

Animal studies were performed in compliance with the guidelines of animal ethics of Qinghai University and were approved by the Animal Care Committee of Qinghai University (no. 20180152).

\section{Patient consent for publication}

Not applicable.

\section{Competing interests}

The authors declare that they have no competing interests.

\section{References}

1. Jaeschke $\mathrm{H}$ and Woolbright BL: Current strategies to minimize hepatic ischemia-reperfusion injury by targeting reactive oxygen species. Transplant Rev (Orlando) 26: 103-114, 2012.

2. Hines IN and Grisham MB: Divergent roles of superoxide and nitric oxide in liver ischemia and reperfusion injury. $\mathrm{J}$ Clin Biochem Nutr 48: 50-56, 2011. 
3. Kupiec-Weglinski JW and Busuttil RW: Ischemia and reperfusion injury in liver transplantation. Transplant Proc 37: 1653-1656, 2005.

4. Urakami H, Abe Y and Grisham MB: Role of reactive metabolites of oxygen and nitrogen in partial liver transplantation: Lessons learned from reduced-size liver ischaemia and reperfusion injury. Clin Exp Pharmacol Physiol 34: 912-919, 2007.

5. Abu-Amara M, Yang SY, Tapuria N, Fuller B, Davidson B and Seifalian A: Liver ischemia/reperfusion injury: Processes in inflammatory networks--a review. Liver Transpl 16: 1016-1032, 2010.

6. Duvigneau JC, Kozlov AV, Zifko C, Postl A, Hartl RT, Miller I, Gille L, Staniek K, Moldzio R, Gregor W, et al: Reperfusion does not induce oxidative stress but sustained endoplasmic reticulum stress in livers of rats subjected to traumatic-hemorrhagic shock. Shock 33: 289-298, 2010.

7. Deng Y, Srivastava R and Howell SH: Endoplasmic reticulum (ER) stress response and its physiological roles in plants. Int J Mol Sci 14: 8188-8212, 2013

8. Xu C, Bailly-Maitre B and Reed JC: Endoplasmic reticulum stress: Cell life and death decisions. J Clin Invest 115: 2656-2664, 2005.

9. Emadali A, Nguyên DT, Rochon C, Tzimas GN, Metrakos PP and Chevet E: Distinct endoplasmic reticulum stress responses are triggered during human liver transplantation. J Pathol 207: 111-118, 2005.

10. Wang R: Physiological implications of hydrogen sulfide: A whiff exploration that blossomed. Physiol Rev 92: 791-896, 2012.

11. Kimura H: Hydrogen sulfide: From brain to gut. Antioxid Redox Signal 12: 1111-1123, 2010.

12. Calvert JW, Coetzee WA and Lefer DJ: Novel insights into hydrogen sulfide--mediated cytoprotection. Antioxid Redox Signal 12: 1203-1217, 2010

13. Kabil $\mathrm{O}$ and Banerjee R: Redox biochemistry of hydrogen sulfide. J Biol Chem 285: 21903-21907, 2010.

14. Jha S, Calvert JW, Duranski MR, Ramachandran A and Lefer DJ: Hydrogen sulfide attenuates hepatic ischemia-reperfusion injury: Role of antioxidant and antiapoptotic signaling. Am J Physio Heart Circ Physiol 295: H801-H806, 2008.

15. Tan EK, Shuh M, Francois-Vaughan H, Sanders JA and Cohen AJ: Negligible oval cell proliferation following ischemia-reperfusion injury with and without partial hepatectomy. Ochsner J 17: 31-37, 2017.

16. Zhang T, Ma Y, Xu KQ and Huang WQ: Pretreatment of parecoxib attenuates hepatic ischemia/reperfusion injury in rats. BMC Anesthesiol 15: 165, 2015
17. Livak KJ and Schmittgen TD: Analysis of relative gene expression data using real-time quantitative PCR and the 2(-Delta Delta C(T)) Method. Methods 25: 402-408, 2001.

18. Wei H, Zhang R, Jin H, Liu D, Tang X, Tang C and Du J Hydrogen sulfide attenuates hyperhomocysteinemia-induced cardiomyocytic endoplasmic reticulum stress in rats. Antioxid Redox Signal 12: 1079-1091, 2010.

19. Georgiev P, Dahm F, Graf R and Clavien PA: Blocking the path to death: Anti-apoptotic molecules in ischemia/reperfusion injury of the liver. Curr Pharm Des 12: 2911-2921, 2006.

20. Jaeschke $\mathrm{H}$ and Lemasters JJ: Apoptosis versus oncotic necrosis in hepatic ischemia/reperfusion injury. Gastroenterology 125: 1246-1257, 2003

21. Shore GC, Papa FR and Oakes SA: Signaling cell death from the endoplasmic reticulum stress response. Curr Opin Cell Biol 23 143-149, 2011.

22. Lee AS: The glucose-regulated proteins: Stress induction and clinical applications. Trends Biochem Sci 26: 504-510, 2001.

23. Szegezdi E, Logue SE, Gorman AM and Samali A: Mediators of endoplasmic reticulum stress-induced apoptosis. EMBO Rep 7: 880-885, 2006

24. Tabas I and Ron D: Integrating the mechanisms of apoptosis induced by endoplasmic reticulum stress. Nat Cell Biol 13: 184-190, 2011.

25. Nakagawa T, Zhu H, Morishima N, Li E, Xu J, Yankner BA and Yuan J: Caspase-12 mediates endoplasmic-reticulum-specific apoptosis and cytotoxicity by amyloid-beta. Nature 403: 98-103, 2000.

26. Szegezdi E, Fitzgerald U and Samali A: Caspase-12 and ER-stress-mediated apoptosis: The story so far. Ann N Y Acad Sci 1010: 186-194, 2003

27. Obert DP, Wolpert AK and Korff S: Modulation of endoplasmic reticulum stress influences ischemia-reperfusion injury after hemorrhagic shock. Shock 52: e76-e84, 2019.

28. Emerson B, Dransfield I, Morton NM and Gray GA: Expression and localisation of $\mathrm{H}_{2} \mathrm{~S}$ metabolising enzymes in the murine myocardium and liver. Nitric Oxide 27: S29-S30, 2012.

29. Han SJ, Kim JI, Park JW and Park KM: Hydrogen sulfide accelerates the recovery of kidney tubules after renal ischemia/reperfusion injury. Nephrol Dial Transplant 30 1497-1506, 2015.

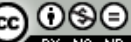

This work is licensed under a Creative Commons Attribution-NonCommercial-NoDerivatives 4.0 International (CC BY-NC-ND 4.0) License. 